\title{
AS CIÊNCIAS SOCIAIS E SEU COMPROMISSO COM A VERDADE E COM A JUSTIÇA ${ }^{1}$
}

\author{
Mauro W. Barbosa de Almeida
}

\begin{abstract}
RESUMO
Este texto trata da responsabilidade do cientista social face à justiça e à verdade, a partir da experiência prática e teórica do autor na Antropologia Social. Embora aborde as Ciências Sociais sob o ponto de vista da Antropologia Social, o texto trata de tópicos em que a atividade do pesquisador e ativista exige a ação cooperativa de juristas, de engenheiros e de biólogas junto com a atuação de sociólogos e geógrafos - tudo o que está envolvido nas situações em que é preciso dizer a verdade e também ajuizar sobre justiça e injustiça na vida social. Noções de justiça e de verdade são armas dos cientistas sociais, e não podem ser abandonadas nas mãos do pensamento conservador.
\end{abstract}

Palavras-chave: Ciências Sociais. Verdade. Justiça. Antropologia

\footnotetext{
${ }^{1}$ [Nota da Comissão Editorial] Aula Magna para o Curso de Graduação em Ciências Sociais da Universidade Estadual de Campinas, proferida em 20 de abril de 2015. Embora pequenos ajustes tenham sido feitos para sua publicação, o texto conservou o formato de apresentação oral. A Comissão Editorial agradece ao autor, como também a Pedro Ferreira e Daniela Manica pela iniciativa de publicar o texto em Mediações.

${ }^{2}$ Professor do Departamento de Antropologia Social da Universidade Estadual de Campinas, Brasil. mwba@uol.com.br
} 


\title{
THE SOCIAL SCIENCES AND THEIR COMPROMISSE WITH TRUTH AND JUSTICE
}

\begin{abstract}
This paper discusses the social scientists responsability in relation to justice and truth, based in the practical and theoretical experiences of the author in the field of Social Anthropology. Although the text adresses the Social Sciences from the perspective of Social Anthropology, it deals with topics in which the researchers and ativists activities require a cooperative action of lawyers, engineers and biologists among the work of sociologists and geographers - all that is involved in the situations when it is necessary to tell the truth and also to judge about justice and injustice in social life. Justice and truth notions are social scientists weapons and they can not be abandoned in the hands of conservative thought.
\end{abstract}

Keywords: Social Sciences. Truth. Justice. Anthropology

O curso de Ciências Sociais compreende, na Universidade Estadual de Campinas (UNICAMP), formações em Sociologia, Ciência Política e Antropologia Social. ${ }^{3}$ Simplificando muito, essas disciplinas correspondem à separação que a sociedade burguesa estabelece entre classes sociais, Estado e família. ${ }^{4}$ Além disso, há a Economia que estuda empresas e mercados, e o Direito que trata de normas que se aplicam a todas essas áreas. Cientistas Sociais não estudam o Direito nem a Economia, e talvez seja ainda mais grave o fato de que a Filosofia, que trata da verdade e da justiça, esteja completamente fora de nosso compartimento acadêmico. Reparem que a vida dos animais é estudo de biólogos, assim como a tecnologia é assunto de engenheiros, embora a vida social esteja permeada de relações com animais e com máquinas. É certo que não se pode tratar de tudo ao mesmo tempo, mas a especialização - traço característico da racionalização que supostamente é o traço dominante da época moderna - não é justificativa para que tomemos essa visão compartimentada da vida social como algo real. Por isso, embora tratando das Ciências Sociais sob o ponto de vista da

\footnotetext{
${ }^{3}$ Gostaria de agradecer Pedro Ferreira pelo convite para proferir essa Aula Magna, e através dele à coordenação do Curso de Graduação em Ciências Sociais da Unicamp.

${ }^{4}$ A expressão refere-se aqui às formas de sociedade constituídas na Europa em que se institui a separação formal entre Estado e Sociedade Civil. No âmbito da Sociedade Civil, a Sociologia nascente no século XIX (e.g.: Tönnies, Durkheim e Weber) distinguiu, além disso, a associação contratual (exemplificada pelo mercado) da "comunidade" (tipificada pelos grupos de parentesco, étnicos e religiosos).
} 
Antropologia Social, vou tratar de tópicos em que a atividade do pesquisador e ativista exige a ação cooperativa de juristas, de engenheiros e de biólogas junto com a atuação de sociólogos e geógrafos - tudo o que está envolvido nas situações em que é preciso dizer a verdade e também ajuizar sobre justiça e injustiça na vida social. ${ }^{5}$

\section{UMA HISTÓRIA DA FRONTEIRA}

Trabalhei durante muitas décadas como antropólogo no sudoeste amazônico, no vale do rio Juruá, que corre paralelo ao Ucaiali, respectivamente no lado brasileiro e peruano da fronteira mais ocidental do país. Trava-se aí hoje em dia 0 destino de muitos povos falantes de três famílias linguísticas, representada pelo povo Kaxinawá e outros do grupo Pano, pelos Ashaninca do grupo Aruaque, e pelos falantes de português descendentes de nordestinos. Esses grupos humanos de diferentes tradições culturais têm algo em comum: eles estão no caminho de negociações para a extensão da estrada BR-364 que ligará o Brasil com portos do Pacífico, começando da recém-terminada e monumental ponte sobre o rio Juruá. De lá até a fronteira peruana são cerca de $140 \mathrm{~km}$ (dos quais 110 já são percorridos por terra até fazendas e sítios), e da fronteira até Pucallpa são $120 \mathrm{~km}$. De lá, seguindo por Huánaco e Ánchash, levará ao porto de Chimbote por mais $450 \mathrm{~km}$, trajeto mais curto para levar soja, trigo, milho e madeira dos Estados da Amazônia e Centro-Oeste até a China e a Costa do Pacífico - palavras textuais da mais recente reunião empresarial-governamental ocorrida em Rio Branco, em 14 de junho de 2014.

Os interesses são muitos. Do lado peruano, toda a fronteira está retalhada por concessões madeireiras e lotes de concessão petrolífera; do lado brasileiro, blocos de exploração de petróleo e xisto. No meio, os territórios remanescentes de comunidades tradicionais e de povos indígenas. ${ }^{6}$ Justamente no planejado trajeto

\footnotetext{
5 Desde já cabe observar que "vida social" não se restringe a humanos biológicos; tampouco deveria excluir, como propõem Weber e Durkheim, o "mundo de vida" das ciências da natureza e o "mundo subjetivo" tratado por algumas correntes da Psicologia.

${ }^{6}$ Sobre os planos de exploração petrolífera na área, ver Sevá (2007, 2015), Sevá e Piedrafita (2007), e Coffaci de Lima, Barbosa de Almeida e Iglesias (2007). Em 7 de agosto de 2013 foi autorizada a $12^{\mathrm{a}}$ rodada de licitações de blocos para a exploração e produção de petróleo e gás natural, incluindo-se aí um bloco vizinho ao mosaico de terras indígenas, reservas extrativistas e áreas protegidas no alto Juruá acreano, antecipado-se aos estudos de impacto (cf. IBAMA-ICMBio 2013, pp. 5-61). E já em 2012 a empresa Georadar realizava prospeção sísmica, antecipando-se ao primeiro debate público sobre o tema (manifestação indígena OPIAC et al. 2012). Agradeço os
} 
que ligará Cruzeiro do Sul a Pucallpa, localiza-se um dos territórios habitados por "indios voluntariamente isolados", isto é, aqueles povos indígenas que, possivelmente desde o início do século $\mathrm{XX}$, recusam o contato direto com nossa civilização, sabendo-se quase nada de sua língua e do que pensam sobre nós exceto 0 fato de que desejam facas e terçados de metal, assim como outras ferramentas dos brancos, mas evitam qualquer contato imediato com brancos ou com índios já articulados a eles. ${ }^{7}$

Esse é um caso particular do fenômeno do desenvolvimento - um trator de acumulação de riqueza que passa por cima de povos locais que não foram consultados previamente e cuja existência será imensamente afetada. 0 assunto ganhará visibilidade quando os efeitos forem irreversíveis, e então nós seremos convocados para "estudos mitigatórios de impacto". Conforme dizia Osvaldo Sevá, nosso colega recentemente falecido e que, engenheiro e cientista social que falava com igual autoridade sobre política energética e suas implicações humanonaturais, nesses casos quem dita as regras são mega-empresas das quais o Estado é executor, e não vice-versa. Ora, esse é um exemplo da seguinte situação: não sabemos o que dizem os "índios voluntariamente isolados" - e há dezenas de outros casos no território brasileiro -, mas podemos dizer que eles expressam sua vontade com atos - a recusa do contato. Do lado de cá, antropólogos e funcionários do Estado agem como aliados desses isolados voluntários, que enquanto minoria estão tendo seu espaço de fuga cada vez mais comprimidos pelas duas frentes de expansão nacionais. ${ }^{8}$

relatos de campo de Antonio Barbosa de Melo (Roxo) em 2012 e 2013 (e-mail e relatório não publicado).

7 Terri Vale de Aquino (e mapas produzidos pela Comissão Pró-Índio do Acre) e José Meirelles (FUNAI-Acre) foram as fontes sobre os índios isolados do Acre, bem como 0 antropólogo Fernando Cesarino, que trabalhou para a FUNAI na área.

${ }^{8}$ Muitos outros exemplos poderiam ser dados, e fazem parte do mesmo quadro. Os caiçaras da costa atlântica, remanescentes das comunidades pescadoras e agrícolas que se estendiam do Paraná ao Rio de Janeiro, foram e estão sendo expulsos paulatina e sistematicamente pela especulação imobiliária, pela indústria turística, pelas obras de infraestrutura (leia-se Usinas Nucleares e Estradas) e pelo conservacionismo autoritário herdado da ditadura militar. Também é o caso de Camponeses-garimpeiros do vale do Tapajós, expulsos em benefício das empresas madeireiras que ganham o monopólio da exploração de recursos em Florestas Nacionais. 


\subsection{Acumulação, destruição, renda diferencial ${ }^{9}$}

Juntam-se assim 0 tema da invisibilização de comunidades humanas e não-humanas em zonas acaparadas pela ânsia devoradora da acumulação capitalista. Estão em curso lutas para trazer à visão as vítimas do processo, e para incorporar lutas locais em movimentos de resistência que apontem para futuros alternativos. Alguns dos meus colegas dizem que está em jogo não apenas a luta contra a expropriação, mas sim uma luta pela diferença. É interessante lembrar que, na linguagem da economia política do século XIX, tratava-se da disputa pela "renda diferencial da terra" - pelas locações que rendem mais. Hoje em dia, segundo novas opiniões, trata-se de disputas pelas diferenças que existem sobre a terra, introduzindo na equação o rendimento possível da madeira, do material genômico, dos minerais na fronteira. Quando se fala do "desenvolvimento sustentável" através de negócios, fala-se da possibilidade de transformar a diferença natural e social em lucro.

Vou pedir licença para falar da grande teórica e militante comunista que foi Rosa Luxemburg. Ela é conhecida pelo seu comunismo libertário, pela sua defesa ferrenha da democracia socialista contra qualquer ditadura, ainda que em nome do proletariado. Mas ela também criticou a teoria da acumulação do capital (isto é, o que chamamos hoje de "desenvolvimento") formulada por Marx de maneira inacabada nos volumes I e II de $O$ Capital.

Segundo Rosa Luxemburg (1970), enquanto no volume I, a acumulação capitalista aparece como um processo histórico de destruição da natureza e de expropriação de camponeses como requisitos iniciais para seu funcionamento, no volume II, essa fase de "acumulação inicial" fica para trás, e em vez disso aparece um esquema que funciona como se fosse uma cobra comendo seu próprio rabo: a acumulação alimenta-se agora de si mesma, e o problema da natureza e dos povos que estão na periferia do sistema deixa de existir. No entanto, já nos tempos de Rosa Luxemburg, como ainda hoje, não há no mundo real capitalista reprodução e muito menos acumulação capitalista auto-sustentada. 0 que há, diz ela, é sempre expansão desequilibrada, caótica e predatória, sem a qual o próprio capitalismo não pode existir. A predação consiste no fato de que a expansão capitalista se alimenta necessariamente de uma periferia constituída por recursos naturais e por povos não-capitalistas. É uma alimentação predatória porque

\footnotetext{
${ }^{9}$ De "Sociodiversidade e desenvolvimento: a Emenda Miranda na Antropologia", palestra realizada na Reunião da Associação Brasileira de Antropologia. Simpósio: Os Antropólogos e os Dilemas do Desenvolvimento. Sessão 1: Desenvolvimento e Sociodiversidade. 4 de julho de 2012, São Paulo, Pontifícia Universidade Católica.
} 
destrói aquilo de que se alimenta como condição de sua vitalidade. Essa periferia é apropriada e destruída ao se converter em mercados consumidores, e em fonte de recursos e matérias-primas. Um dos exemplos de Rosa é o ciclo da borracha no Putumayo peruano-colombiano, 0 assunto que pesquisei de perto durante anos porque continuava em curso quase um século depois do assassinato da grande teórica. Mas para ela essa não era uma fase "primitiva" do capitalismo, e sim o modo necessário de crescimento do capital.

Meio século depois do assassinato de Rosa Luxemburg em 1919, o economista romeno Georgescu-Roegen (1986) afirmou, em 1971, que todo crescimento econômico, capitalista ou não, é de natureza predatória no seguinte sentido: transforma energia rica em diversidade em energia com baixa diversidade. Em outras palavras, toda atividade econômica gera entropia. Isso significa em miúdos tanto destruição irreversível da energia acumulada sob forma de petróleo e carvão, como aquecimento do planeta. 0 economista romeno fazia assim uma síntese de Carnot com Marx.

0 jovem Carnot, refletindo por volta de 1820 sobre os limites ao funcionamento de máquinas a vapor, chegou à Segunda Lei da Termodinâmica. A Primeira Lei diz que a energia se conserva mudando de forma, mas a Segunda Lei diz que há um limite no aproveitamento da energia quando ela se transforma de sua forma-calor para sua forma-trabalho. Mais especificamente ainda, Carnot descobriu que é preciso uma diferença de calor - diferença entre quente e frio para converter calor em trabalho (para que um peso seja levantado, para que uma roda gire erguendo um peso) ${ }^{10}$. A mensagem da Segunda Lei é que, ao ser usado para produzir trabalho, essa diferença inicial entre um reservatório quente e um reservatório frio é perdida. A Segunda Lei diz, em suma, que enquanto a energia se conserva, ela por assim dizer se degrada ao transitar de estados nos quais há mais diferença (reservatório quente e reservatório frio) para estados onde há

\footnotetext{
10 "A produção do movimento nas máquinas a vapor é sempre acompanhada de uma circunstância na qual devemos fixar nossa atenção. Tal circunstância é (...) a passagem [do calórico] de um corpo no qual a temperatura é mais ou menos elevada, para um outro no qual ela é mais baixa." (CARNOT, Sadi. Réflexions sur la Puissance Motrice du Feu sur les Machines Propres a Développer cette Puissance. Paris, 1824, apud MAURY, 1986, p.51). Carnot refere-se ao fluxo de "calórico", que foi descartado posteriormente (inclusive pelo próprio Carnot em anotações não publicadas) em favor da noção de um fluxo de energia sob a forma de calor. "Na época em que Carnot viveu, a Primeira Lei da Termodinâmica, a conservação da energia, não era conhecida. No entanto, os argumentos de Carnot foram delineados tão cuidadosamente que eles são válidos mesmo assim (...). Portanto, a chamada Segunda Lei da Termodinâmica foi descoberta por Carnot antes da Primeira Lei!" (FEYNMAN, 1963, p. 44-2, 44-3).
} 
menos diferença (reservatórios mornos). A perda de diferença, que resulta da perda da capacidade para realizar trabalho é medida como aumento de entropia. Entendemos assim que a mensagem de Rosa Luxemburg foi reformulada por Georgescu-Roegen com a linguagem da termodinâmica da seguinte maneira: a acumulação industrial se alimenta de aumento de entropia, de destruição da diferença (GEORGESCU-ROEGEN, 1986; KÜMMEL, 2011).

\section{A SOCIOLOGIA COMO AUTOCONSCIÊNCIA CRÍTICA DA SOCIEDADE OCIDENTAL}

Voltemos ao tema inicial, depois desse exemplo de como questões de violência do Estado e da natureza do progresso se imbricam. Trata-se de nosso papel face a processos como esse.

Entrei no Curso de Ciências Sociais da USP em 1969, logo em seguida ao Ato Institucional número 5, que instituiu a fase mais negra da ditadura militar em nosso país e teve como um de seus efeitos imediatos a expulsão de muitos dos melhores cientistas sociais das universidades, particularmente no Rio de Janeiro e em São Paulo. Naquela época, era uma tarefa importante resistir intelectualmente contra a ditadura. Acho que isso explica o tom e o clima das grandes aulas que tive na época. E chego agora à lição principal que tive dos meus jovens professores que haviam sobrevivido ao expurgo direitista e obtuso. A lição era uma primeira resposta à pergunta que é o título dessa minha aula. Ela dizia que a característica de toda Ciência é desvelar as aparências em busca daquilo que produz a aparência. Mas ao fazer isso, o cientista social necessariamente faz crítica da sociedade. Ou em outras palavras: a Sociologia tem como tarefa atuar como autoconsciência crítica da sociedade contemporânea.

Marialice Mencarini Forachi, a professora encarregada do curso de Sociologia, dava como exemplo a análise da forma da mercadoria feita por Marx no primeiro capítulo do Capital, que começa de maneira muito abstrata e termina com a crítica do fetichismo da mercadoria. Desvelar a aparência do dinheiro como fetiche equivale a criticar a sociedade que se reconhece na forma de coisas que parecem dotadas de um poder próprio para comprar qualquer coisa - de tênis produzidos por meninos do Sri Lanka, a educação e saúde. Essa era a visão da Sociologia crítica de Theodor W. Adorno, Max Horkheimer, Walter Benjamin e Herbert Marcuse. Criticando uma Sociologia positivista, que toma como meta da ciência a descrição do que existe, esses autores defendiam uma Sociologia negativa e não positivista (que para eles era o mesmo que positiva). 
Marcuse escreveu Razão e Revolução (1978) para defender a tese de que, na origem da Sociologia crítica, está a tese hegeliana de que "o que é real é racional, e o que é racional é real". Para os intérpretes da "esquerda hegeliana", a mensagem aí contida é: se o real não é racional, deve ser negado em nome da razão. Em outras palavras: se a realidade social é irracional, cabe então transformá-la. Essa interpretação de Hegel foi retomada por Marx na fórmula famosa: os filósofos já interpretaram bastante o mundo, cabe agora transformá-lo. Marcuse não se limitou a afirmar o caráter crítico da Sociologia, mas escreveu dois livros que influenciaram o movimento de rebelião estudantil de 1968, combinando ideias de Freud e de Marx numa crítica à unidimensionalização do humano na sociedade industrial, que equivalia em Marcuse à repressão ao "polimorfismo perverso" associado ao corpo infantil. Isso significa que a Sociologia crítica não excluía a noção de inconsciente, nem a noção de que 0 princípio do prazer é parte integrante do humano. Contudo, a crítica à "ideologia da sociedade industrial", escrita sob o impacto da adesão das massas ao nazismo na Alemanha e da burocratização do socialismo de Estado na União Soviética, não propunha soluções nem modelos alternativos (cf.: MARCUSE, 1967; HORKHEIMER e ADORNO, 1972; ADORNO, 1975). Essa atitude crítica pode ser lida nos manifestos e grafitti de estudantes em 1968, que rejeitavam a ordem existente mas não diziam o que colocariam no seu lugar; não se contentavam com o possível, diziam: "seja realista: peça o impossível".

\subsection{A metáfora da caverna}

Afirmei que a Ciência Social tem o papel de afirmar a verdade contra a inverdade, e julgar o que é injusto e o que é justo. Essa é uma atividade crítica, que é sempre possível mesmo quando não sabemos mais precisamente o que por no lugar do que existe. Essa vocação da Ciência como negação da aparência foi descrita há dois mil anos e meio por Platão com a chamada metáfora da caverna.

A metáfora de Platão descreve "o estado de nossa natureza relativamente à instrução e à ignorância”. Isto é: trata do modo normal pelo qual vemos a realidade.

Imagina homens em morada subterrânea, em forma de caverna, que tenha em toda a largura uma entrada aberta para a luz; estes homens aí se encontram desde a infância com as pernas e 0 pescoço acorrentados, de sorte que não podem mexer-se nem ver alhures exceto diante deles, pois a corrente os impede de virar a cabeça; a luz 
lhes vem de um fogo aceso sobre uma eminência, ao longo atrás deles (PLATÃO, 1973, p. 105)

A caverna: os cinemas de shopping, a televisão monopolística, as redesmonstro como Google e Facebook. Ou ainda, para os que viram o filme: Matrix, onde pessoas aprisionadas têm como real um mundo virtual plugado nos seus cérebros. São como escravos aprisionados para gerar lucros para uma elite.

Platão continua a analogia dizendo que, para acessar 0 mundo da realidade, é preciso literalmente quebrar as correntes que aprisionam o corpo, e sair da realidade virtual para o mundo lá de fora. Mas a história não termina aí, porque aqueles que regressam à caverna para falar sobre o que há fora da caverna correm 0 risco de serem linchados pelos antigos companheiros que continuam plugados na visão das aparências. Para voltar à linguagem da escola de Frankfurt: a crítica é rejeitada em nome da "sublimação repressiva" que oferece satisfação garantida e controlada pela indústria cultural. A atitude de Platão é marcada pela memória da condenação e execução de seu mestre Sócrates sob a acusação de corromper a juventude ateniense com sua doutrina da verdade. A moral da história é que para dizer a verdade é preciso insurgir-se contra a autoridade, e sair da caverna para a rua, onde bate o sol. Ou refugiar-se na Academia, como a que Platão fundou. Deve-se notar que a sabedoria, porém, não está apenas na academia. Seguindo Antonio Gramsci, podemos dizer que "todos os homens são filósofos". ${ }^{11}$ A "filosofia espontânea" do homem comum é o bom senso, que

11 "[C]abe demonstrar [que] todos os homens são 'filósofos', definindo os limites e as características desta 'filosofia espontânea', própria de 'todo mundo', e os da filosofia que é contida: (1) na própria linguagem, que é um conjunto de noções e de conceitos determinados e não somente de palavras gramaticalmente dotadas de conteúdo; (2) no senso comum e no bom senso; (3) nas religiões populares e portanto também em todo o sistema de crenças, superstições, opiniões, modos de ver e de agir que se designam no que se chama geralmente de 'folclore'" (GRAMSCI, 1875, p. 1375). Sobre a distinção entre "bom senso e senso comum" ver Gramsci (1875, p. 1063). Pode-se lembrar aqui o que Kant disse sobre uma das três "faculdades superiores de conhecimento" que é a capacidade de julgar ou Urteilskraft: "A falta de capacidade de julgar (Urteilskraft) é propriamente aquilo que se chama de tolice (ou burrice), e não há como remediar essa deficiência. Uma mente obtusa e estreita, à qual não falta senão um grau adequado de entendimento e conceitos apropriados, pode ser muito bem aperfeiçoado, chegando até à erudição. (...) [M]as não é raro encontrar homens muito eruditos que, no uso de sua ciência, deixam amiúde entrever [essa] deficiência, que jamais pode ser melhorada.” (KANT, 1966, A134/B172). 
compartilha com a filosofia a atitude crítica face tanto ao "senso comum" quanto à religião. ${ }^{12}$

Aqueles que buscam ver além da imagem da aparência - como os sábios Kaxinawá que distinguem o mundo visível do mundo verdadeiro acessível através do sonho ou de experimentos com o corpo -, esses são os xamãs, as mães-desanto, os líderes de revoltas camponesas, os inventores de sistemas de parentesco, de variedades de plantas cultivadas, de mitos e de filosofias indígenas. Eles também fogem do conforto da aparência e buscam outros modos de vida, mais verdadeiros que os que estão sob nossos olhos. Mas a vida de xamãs e de pais-desanto não é moleza. Sobre isso voltarei adiante, mas desde já adianto minha posição: há cientistas sociais dentro da academia e fora da academia, entre humanos e entre não-humanos. Também há cães-mestres e aves-professoras! $!^{13}$

A vocação intelectual crítica, como a dos xamãs antigos, requer a capacidade de aceitar a impopularidade, se não coisa pior, quando a violência de Estado se dissemina nas massas como fascismo molecular (DELEUZE e GUATTARI, 1980). O pensamento "negativo" não é apenas incômodo: em situações de fortalecimento do "fascismo de Estado" e de sua versão molecular, ele envolve risco de vida. Notem que não estou menosprezando a sabedoria popular. Também aqui há uma distinção entre o senso comum e o bom-senso, isto é, entre aqueles que passam adiante a imagem da aparência e aqueles que inventam e inovam, buscando a luz do saber que vai além das aparências, como mencionado acima.

Adorno, Horkheimer e Marcuse, exilaram-se nos Estados Unidos para escapar à aniquilação de intelectuais efetuada pelo Estado Nazista; enquanto Walter Benjamin perdeu a vida durante o percurso. Eles defendiam, num mundo em guerra que evoca assustadoramente tendências atuais, a busca da verdade

12 "A filosofia é a crítica da religião e do senso comum e a superação destes; neste sentido, a filosofia coincide com o "bom senso" (GRAMSCI, 1875, p. 1063).

${ }^{13}$ Sobre cães mestres, ver Süssekind (2010, p. 130). Sobre aves professoras, ver Mesquita (2012, p. 71). Os escolásticos tinham menos dificuldade do que os modernos para reconhecer a capacidade de animais para escolher com base em raciocínio: "Os cães, com efeito, ao perseguirem os veados, quando se encontram diante de três caminhos; pelo olfato procuram sentir se 0 veado seguiu pelo primeiro ou segundo caminho. Percebendo que não passou por eles, vão seguros por este caminho sem usar do olfato, como se usassem de um silogismo divisivo com o qual pudessem concluir que o veado fugiu por este caminho, visto que não passou pelos dois outros, não havendo outros. Logo, parece que a eleição [escolha] pertence aos animais irracionais" (TOMÁS DE AQUINO, 2005, p. 187, Questão 13, artigo 2; cf. Questão 49, artigo 4). A questão da capacidade canina de raciocínio é retomada pela discussão filosófica contemporânea (FLORIDI, 1997). 
guiada pela razão, a busca da resistência contra a tolerância repressiva (MARCUSE, 1967, p. 82); ou seja, contra a aparente liberdade de opinar seguindo editoriais que nos ensinam o que dizer, de escolher filmes seguindo as ofertas da indústria de consumo, de comer seguindo as opções mercantis.

\subsection{Um princípio de injustiça}

Pode parecer difícil julgar o que é justiça em geral, mas é menos difícil perceber a injustiça ante nossos olhos. Somos hoje bombardeados na imprensa e nos intelectuais que ela promove pela doutrina segundo a qual os projetos de transformação revolucionária da sociedade fracassaram. A prova seria 0 fim do socialismo na União Soviética e a regressão capitalista da China. Segundo uma visão hoje hegemônica, o individualismo possessivo é eficiente, a competição é o melhor dos mundos possíveis; e seria próprio da natureza humana buscar 0 próprio bem-estar à custa dos outros. Em resumo, o mercado é o melhor dos mundos sociais possíveis; é a realização da eficiência conforme a natureza humana. Devemos então enterrar a tradição da crítica social, cujos fundamentos vêm no mínimo de Rousseau. É o que dizem as aparências no fundo da caverna.

Vamos examinar mais de perto essa doutrina, na forma de um princípio que era, pelo menos até há poucos anos, ensinado em manuais de economia no capítulo que perversamente se chamava de "Economia do Bem Estar". Eis o Princípio de Pareto: Uma situação social é ótima quando não é possível aumentar o bem-estar de alguém sem reduzir o bem-estar social de outra pessoa. Ou, na versão de um manual de microeconomia: "Diz-se que qualquer organização é ótima ou eficiente no sentido de Pareto quando qualquer reorganização que aumente 0 valor de uma variável reduz necessariamente 0 valor de outra" (FERGUSON, 1985, p. 151; ver também SAMUELSON, 1976, p. 462 nota 12).

A ideia básica é que não se pode julgar o bem-estar coletivo comparando o bem-estar de indivíduos. Em vez disso, o princípio de Pareto postula que o bemestar coletivo é ótimo quando a distribuição de bens não pode ser alterada sem que alguém se sinta prejudicado. Ada possui três garrafas de vinho e Bill tem três pães. Esse estado de coisas ainda não é ótimo se há maneiras de redistribuir o vinho e o pão de tal modo que tanto Ada como Bill sintam um aumento de bemestar. Se Bill for abstêmio, nenhuma redistribuição de pão em troca do vinho de Ada melhorará o seu bem-estar: nesse caso, o estado de coisas já será "ótimo" porque não pode ser melhorado sem prejudicar Bill. Aqui, Ada e Bill agem 
cooperativamente quando cada um de seu lado melhora seu bem-estar através da troca de parte do que é seu por uma parte do que é do outro (HILDENBRAND e KIRMAN, 1976).

Ada e Bill não precisam barganhar diretamente: 0 mercado faz isso para eles através do sistema de preços. Conclusão: "o sistema de preços em concorrência perfeita conduz ao ponto do bem-estar social máximo" (FERGUSON, 1985, p. 545, nota 6). Essa conclusão é chamada de "Teorema Fundamental da Economia do Bem-Estar".

0 que pode dar errado? 0 mesmo manual lembra uma razão: "0 exemplo clássico de uma deseconomia externa envolve a viúva pobre, que se sustenta trabalhando como lavadeira, e a fábrica próxima à sua casa, cuja fumaça escurece a roupa. Exemplo mais recente e relevante é a poluição atmosférica." (FERGUSON, 1985, p. 549). Bem, isso poderia ser corrigido talvez por regras ambientais - 0 Estado cobraria uma taxa da empresa; e por que é que a costureira não muda de endereço?

Mas há outra razão mais séria. Pode ser que Ada possua todas as três garrafas de vinho e todos os três pães. Nesse caso não há nada a fazer, trocar. Vocês podem pensar que Ada prefere comer em companhia de Bill a se encher de vinho e de pão. Mas nesse caso, o sistema de preços de mercado já não produz 0 mesmo resultado que a interação social, a não ser que Bill seja garoto de programa (HILDENBRAND e KIRMAN, 1976).

Para um exemplo mais realista, deixemos A e B nos manuais de economia e contemplemos um quarteirão comercial cujos armazéns estão repletos de comida para ser exportada, em uma região assolada pela fome. A situação aplicouse em muitos casos históricos na Irlanda, na Índia e na África, Sudeste Asiático e no Brasil, durante secas famosas no nordeste brasileiro. Aplicando o princípio de Pareto, retirar comida do armazém e distribui-las para os famintos não melhora 0 bem-estar social, porque afeta o bem-estar do dono do armazém. A situação de mortandade coletiva ao lado de armazéns abarrotados de comida é ótima segundo o critério de Pareto. Como diz o economista de origem indiana, Amartya Sen, cuja obra foi dedicada ao estudo da desigualdade social e à crítica da "economia do bem-estar" acadêmica: "Um ótimo de Pareto pode ocorrer com algumas pessoas em miséria extrema e outras rolando no luxo, desde que os miseráveis não possam melhorar sem diminuir o luxo dos ricos." (SEN, 1987, p. 32).

Há duas suposições silenciadas por trás do sinistro ótimo de Pareto: (1) as únicas transferências de riqueza permitidas são aquelas que se dão no mercado, isto é, onde as transferências ocorrem voluntariamente entre agentes movidos por 
seus próprios interesses individuais; e (2) a propriedade privada é garantida pelo Estado. Essa segunda suposição é de fato essencial, pois é a violência policial que impede que os armazéns sejam arrombados pela multidão faminta.

Exemplos da aplicação do primeiro axioma: extinção de saláriodesemprego; proibição de reforma agrária com transferência de terra sem concordância plena do latifundiário. Exemplo de aplicação do segundo axioma: a expulsão violenta de ocupantes de territórios urbanos e rurais apropriados privadamente. Em suma, a regra de justiça aparentemente razoável - não melhorar sua vida à custa da vida do outro - é a consagração da desigualdade no acesso a meios de vida e da violência de Estado.

\subsection{Violação do Princípio de Pareto melhora o bem-estar coletivo}

Há muitos sinais contrários ao dogma da propriedade privada e ao princípio de Pareto. De fato, o próprio capitalismo colocou a informação como principal força produtiva no século XXI (BENKLER, 2006). Mas a informação é difícil de empacotar e de privatizar: ela escapa às fronteiras, como mostram vazamentos célebres e como a rotina dos jovens que acessam filmes e músicas sem pagar direitos autorais demonstra melhor ainda. Isso não é visto como roubo, e sim como a forma justa de circulação da informação. As redes de circulação de informação de forma não-mercantil apelam para a solidariedade e para a cooperação, resultando em cadeias de invenção coletiva cujos resultados se disseminam gerando mais invenção e beneficiando a todos.

As sociedades indígenas fornecem outro exemplo de redes de circulação de conhecimentos tradicionais de boca-em-boca, sem pagamento pelo mercado, em um processo que antecipou as Wikipedias e resultou em milhares de mitos produzidos em redes que atravessam as Américas e ainda podem ser escutados ao vivo.

As comunidades camponesas continuam produzindo novas variedades de plantas cultivadas, incluindo-se aí centenas de qualidades de mandioca, dezenas de tipos de banana, de feijões, de pimentas, junto com uma igualmente enorme variedade de modos de preparar alimento, tudo isso acompanhado de sistemas metafísicos e morais nos quais plantas podem ser tratadas como parentes e como pessoas. 
Como diz Viveiros de Castro, há outros mundos possíveis, nos quais o individualismo possessivo não é a norma principal e onde o Princípio de Pareto jamais seria levado a sério. (DANOWSKI e VIVEIROS DE CASTRO, 2014)

\section{A responsabilidade do Cientista Social para com a VERDADE E A JUSTIÇA}

Como é que isso afeta o cientista social? Sou antropólogo e como tal sou chamado para fazer laudos sobre situações de injustiça que envolvem comunidades em relação com o Estado e empresas privadas. Uma situação típica com que meus colegas e eu nos deparamos - e há gente trabalhando dos dois lados da cerca - é a expulsão de índios e de camponeses tradicionais de seus territórios, para benefício de empresas madeireiras, de projetos de hidrelétricas, de unidades de conservação autoritárias. 0 que se exige do sociólogo nesses casos?

Eis o que diz Noam Chomsky (1996, p.56), o grande intelectual anarcosindicalista: "A responsabilidade do intelectual (escritor) enquanto agente moral é tentar trazer a verdade sobre assuntos de importância humana para uma audiência que possa fazer alguma coisa para mudar."

Reparem que invoquei Chomsky, que expressou a noção de que a tarefa principal dos intelectuais é dizer a verdade para aqueles que podem mudar a realidade de opressão e de injustiça. Hoje em dia, porém, a visão em voga é aquela que rejeita qualquer noção de verdade e de justiça, junto à própria noção de Razão. Essa visão é associada ao chamado "pós-modernismo", e Michel Foucault é invocado em apoio a essa filosofia micropolítica, junto com Gilles Deleuze. ${ }^{14}$ Creio que essa visão em voga traz confusão na luta pelo desvelamento da verdade e contra a injustiça, deixando de lado outras facetas e implicações presentes na obra desses grandes pensadores da vida social (CHOMSKY, 1989).

Em um debate travado com militantes maoístas em 1972, pouco depois da revolta parisiense de 1968, Foucault (1985) criticava todo e qualquer tribunal, que como outros órgãos e o Estado, têm como efeito "apresar, dominar e jugular" attraper, maîtriser, juguler." Mas nesse mesmo debate, chama a atenção que Foucault defende uma "justiça popular", que embora sem tribunais, procederia ao julgamento e à execução das classes exploradoras pelas massas populares. Tratava-se para Foucault, nesse debate, de criticar a ideia da justiça

\footnotetext{
${ }^{14}$ Uma visão de conjunto do pós-modernismo em confronto com a "teoria crítica" está em Habermas (1988), embora um pouco envelhecida.
} 
institucionalizada, uma "instância neutra entre o povo e seus inimigos, e suscetível de estabelecer a separação entre 0 verdadeiro e 0 falso, 0 culpado e 0 inocente, o justo e o injusto". Nessa rejeição, Foucault (1985, p. 341) associava "uma ideia, uma forma, uma regra universal de justiça" e a noção correlata de uma "verdade universal" ao poder localizado em tribunais. Essa justiça, diz ele, ainda que nas mãos de um "tribunal revolucionário", seria sempre um meio de "desarmar [as massas] na luta real em benefício de uma arbitragem ideal" (FOUCAULT, 1985, p. 345).

\subsection{Economias Morais e Princípios Locais da Justiça}

Resta 0 fato de que Foucault apoiava no mesmo texto uma justiça das massas populares. E isso sugere que é possível rejeitar a ideia de "justiça universal" em favor de uma "justiça local”. E seria então possível estender essa ideia, por analogia, a uma noção de "verdade parcial".

Isso nos leva à noção de "economia moral", utilizada por historiadores, antropólogos e cientistas políticos para dar conta das razões subjacentes a movimentos populares insurgentes. 0 princípio básico da "economia moral" é a antítese do princípio de Pareto: é a ideia de que há um mínimo de meios de vida a que tem direito todo ser humano, abaixo do qual se justifica a revolta e a contraviolência contra aqueles que detêm esses meios de vida em excesso sem partilhálos. Essa noção é invocada em rebeliões camponesas e urbanas (BARRINGTON MOORE JR., 1966; THOMPSON, 1991; SCOTT, 1976). Ela justifica a invasão do armazém onde está a comida que pode salvar da fome milhares de desabrigados.

É útil ressaltar que não se trata aqui de uma teoria científica da exploração como base da desigualdade social. Não se trata tampouco da abolição da desigualdade social em geral. 0 que está presente aqui é um julgamento popular - no sentido de uso da faculdade de julgar das pessoas comuns -; um juízo coletivo sobre o que é certo e o que é errado, apoiado na distinção entre o falso e 0 verdadeiro, e 0 justo e 0 injusto (é verdade que todas as pessoas têm direito à vida, e é injusto que o povo morra de fome enquanto uma minoria nada na abundância). Trata-se de uma "filosofia espontânea" que contém uma teoria sobre a ordem social - e não apenas uma irrupção irracional da violência coletiva.

Revoltas populares supõem um mínimo de organização, mas não apenas isso. Também pressupõem a existência de princípios de justiça, que podemos tomar no sentido da justiça local, e de afirmações aceitas como verdadeiras no sentido da verdade parcial - sobre justiça local e verdade parcial ver, 
respectivamente, Elster (1992) e Affonso da Costa e French (2003). Juízos desse tipo estão presentes na rebelião de Canudos e de Contestado; na Guerra Revolucionária do Vietnã; na resistência dos quilombolas; nas inúmeras lutas indígenas; e nas ocupações de edifícios na cidade de São Paulo.

"Economias morais" se referem a éticas populares que se aplicam não apenas nas rebeliões populares, mas também no trabalho cooperativo, no tratamento de pedintes e de doentes, na solidariedade aos viajantes, nesse caso na forma que tem sido chamada de "economias de dádiva" nas quais a troca de bens visa acumular relações com pessoas e não acumular dinheiro (GREGORY, 1982). Tais éticas, que contrastam com a ética do individualismo possessivo e mercantil, e com a ética da predação competitiva, estão presentes também no micro-tecido da vida urbana, em relações de vizinhança, em redes informais, em neocomunidades que ocupam espaços da cidade, talvez para fazer skate, para pintar, para brincar ou para viver na rua. ${ }^{15}$ Assim como conhecimentos tradicionais sofisticados e um pensamento matemático sutil estão presentes em tradições culturais antigas, há filosofias éticas e morais elaboradas em tradições camponesas e urbanas.

A noção de uma justiça popular invocada por Foucault supõe, assim, uma economia moral, que são juízos éticos locais que dispensam tribunais institucionalizados. Mas aqui é preciso atentar para não confundir a "economia moral" - a parte de "bom senso" da filosofia espontânea popular - com "economias de desespero" que buscam bodes expiatórios para o sofrimento e procuram o culpado no vizinho mais fraco. Esse mau "senso comum" é a base do fascismo molecular (expressão de Deleuze à qual voltaremos) manifestado no linchamento de pequenos ladrões de rua.

Analogamente, também nos aparelhos de Estado, nos tribunais e na administração, há mais de um princípio de justiça. Há um "direito apanhado nas ruas", que não significa outra coisa senão uma aproximação, por parte de juízes e advogados que militam no interior da máquina de Estado, com filosofias populares. Ora, quando se é "pé-de-moleque", minoria indígena, mãe-de-santo, peão-de-trecho, trabalhadora terceirizada - ou melhor, quando não se pertence a "massas populares", mas a grupos diferentes e minoritários no interior de nações - é essencial ter aliados que, no interior dos tribunais, defendam a "justiça como fairness", que trate diferenciadamente as minorias e as proteja não só contra a violência de Estado, mas também contra o "fascismo molecular" das maiorias.

${ }^{15}$ Sobre 0 caso do skate, cf. Ferreira (2015). 
Hoje em dia esses aliados são Procuradores da República, os Defensores Públicos - vários deles com formação na Antropologia e em outras Ciências Sociais - que lutam em favor dos injustiçados e dos excluídos. ${ }^{16}$

Ora, estou dizendo aqui, com apoio em pensadores como Chomsky, que as Ciências Sociais precisam retomar a defesa da justiça e da verdade, deixada hoje em dia a critério de filósofas da ética como Martha Nussbaum, por economistas éticos como Amartya Sen, e por filósofos do direito como John Rawls. Este último afirma que "leis e instituições, não interessa o quanto possam ser eficientes e bem organizadas, devem ser reformadas ou abolidas se forem injustas" (RAWLS, 1971, p. 5$)^{17}$

É claro que essa visão rejeita o critério de Pareto ${ }^{18}$ : se suas consequências são injustas, seus pressupostos devem ser "reformados ou abolidos", e em primeiro lugar o pressuposto do direito absoluto à propriedade privada e do uso da violência de Estado para garantir esse direito absoluto. Cabe notar que, depois do colapso do mercado financeiro de 2008, receberam prêmios Nobel: Amartya Sen, eminente crítico do critério de Pareto e defensor de uma economia baseada na ética, e Elinor Ostrom, jurista de formação e autora de obra igualmente vasta sobre 0 valor da cooperação e da propriedade coletiva.

\subsection{Estados totalitários, Estados fascistas, e outros Estados}

Gilles Deleuze é justamente apreciado como mestre e orientador das gerações atuais. Deleuze contrastou a "macropolítica" que se dá no plano molar das classes e do Estado, com a "micropolítica" molecular de massas de partículas que interagem por contato local. Mas Deleuze não tratou essa distinção como um dualismo exaustivo. Ele apontou para um "fascismo molecular", para um "microfascismo" que é o prolongamento do fascismo de Estado, e distinguiu Estados fascistas de Estados totalitários, embora sem tratar de Estados que não

\footnotetext{
${ }^{16}$ Princípios de justiça localizados no tempo e no espaço são exemplificados pela afirmação de direitos humanos e em tratados multinacionais como a Convenção 169 sobre Povos e Comunidades Tradicionais.

${ }^{17} 0$ objetivo de Rawls é chegar a um "conjunto de princípios" para "escolher entre diversos arranjos sociais que determinem [um] divisor de vantagens, e para servir de base para um acordo sobre as parcelas distributivas" (RAWLS, 1971, p. 4).

${ }^{18}$ Pareto, ao tratar do "problema de ofelimidade coletiva máxima" (isto é, de "bem-estar coletivo máximo"), esclareceu que deixou "o estabelecimento das regras de distribuição que são consideradas apropriadas" para "a província da Sociologia” (PARETO, 1955, p. 87). Podemos então dizer que a Sociologia terceirizou o problema da justiça distributiva para a filosofia.
} 
chegam a ser nem totalitários nem fascistas, mas nos quais pode fermentar 0 microfascismo racista, anti-imigrante, anti-"pobre". As diferenças talvez se encontram na margem de ação para que operem, no interior da sociedade, rizomas de resistência e de diversidade, opondo-se à contínua interpelação que "transforma indivíduos em súditos".

Movimentos operários e movimentos anarquistas, assim como as ações que se dão no interior de aparelhos de Estado contra a maré montante do individualismo possessivo, dependem da existência de um mínimo de princípios de justiça que sirvam de anteparo possível - não que sejam de fato aplicados, ou que sejam na maior parte dos casos aplicados - para a injustiça extrema que é a eliminação sistemática, pura e simples dos diferentes e dos opositores.

\section{RAZÃO REVOLUCIONÁRIA}

Noções de justiça e de verdade (ainda que se trate agora de justiças locais e de verdades parciais, e de uma razão destranscendentalizada e não de uma Razão Universal), são armas dos pesquisadores sociais, e não podem ser abandonadas nas mãos do pensamento conservador. Hoje em dia o pensamento hegemônico conservador, que consagra, sabendo ou não, o individualismo possessivo e 0 princípio de Pareto, invocam argumentos de aparência racional, enquanto os intelectuais críticos parecem renunciar às armas da crítica apoiada em juízos de verdade e de justiça. Contra esse sequestro da ideia de razão pelo conservadorismo, defendi nesta aula a ideia de que há uma razão revolucionária, que é destrutiva e construtiva e que não se confunde com cânones e regras da razão. A razão revolucionária não é a razão canônica (AFFONSO DA COSTA, 1997).

Voltemos, para concluir, à terra firme. Há agora uma nova dimensão do problema, que é a combinação de princípios de justiça com a racionalidade popular. Mas o assunto não para aí, porque a justiça abrange agora direitos coletivos humanos e não humanos, ao mesmo tempo que ela é fruto de manifestações de humanos e de não-humanos. Esse último ponto será objeto de meus comentários finais.

Há direitos coletivos, que entraram na Constituição, nas Disposições Transitórias, na noção de títulos coletivos sobre terras quilombolas. Eles também aparecem nas Terras Indígenas e nas Reservas Extrativas. São diferenças que perturbam o dualismo jurídico que contempla a propriedade privada e a propriedade Estatal como formas únicas e complementares de atribuir direitos a agências humanas sobre a Terra e sobre a natureza como um todo. Mas há ainda 
direitos animais, ou melhor dizendo: direitos humanos que se estendem a nãohumanos.

0 ministro que levou seu cão ao hospital em uma ambulância alegando que o animal "era um ser humano como outro qualquer" tinha razão. Não são os biólogos quem definem quem é humano do ponto de vista ético-político. Como ensina Nádia Farage (2013), é bumano quem é tratado com a dignidade devida a humanos. Assim como pessoas podem ser reduzidas à condição de ratos em campos de concentração - e aí a luta não é apenas para sobreviver, mas para viver humanamente -, ratos podem e devem ser tratados humanamente. Ontologias são históricas (HACKING, 2004).

Há em muitos povos - da América do Sul amazônica e andina, na Índia e no oriente, na África e na Austrália - filosofias que não estabelecem fronteiras ontológicas ou morais entre humanos e animais. Para índios sul-americanos, os animais já foram humanos "no tempo em que os bichos falavam", como tem acentuado Viveiros de Castro (DANOWSKI e VIVEIROS DE CASTRO 2014); e acrescento que isso não está longe da afirmação de Wallace (1858) e de Darwin (1964) de que já houve um tempo em que "os humanos não falavam”. Mas será que é preciso falar para ter direitos humanos? Ora, se fosse assim, recém-nascidos e por-nascer, mudos e afásicos, loucos e comatosos, poderiam ser desmanchados para uso de seus órgãos. Mas não é assim: há aí um território de luta ontológica onde se decide quais entes são parte da sociedade enquanto sujeitos de direitos, $\mathrm{e}$ quais são aqueles que, como os escravos no passado, são "animais", ou ainda, "meras coisas".

Não é preciso falar, porque, como sabem os economistas, consumidores expressam suas preferências por meio de suas ações, isto é, pelas ruas e sites que frequentam e pelo que compram neles. Animais expressam suas preferências pela vida e contra a escravidão tentando escapar de corredores da morte e perambulando por muros e terrenos baldios. Como escreveu dramaticamente 0 escritor norte-americano David Wallace (1858), lagostas expressam suas "concepção de justiça" tentando escapar de caldeirões ferventes. Ademais, acredito que animais - pelo menos alguns que conheço -, além da capacidade de raciocínio a que fizemos referência mais acima, compartilham com humanos sentimentos de dor e de compaixão. ${ }^{19}$

\footnotetext{
${ }^{19}$ Esse ponto foi defendido exaustivamente por Darwin; antes dele, Rousseau e em seguida Schopenhauer (1998) apoiaram nessa verdade de fato suas teorias éticas.
} 


\subsection{O véu da ignorância com animais e plantas}

Falei antes sobre a teoria da justiça de Rawls. Este filósofo do direito imaginou uma curiosa assembleia constituinte, que funciona assim. Os representantes que se destinam à assembleia colocam, ao entrarem, um capuz sobre a cabeça, como os óculos de 3-D dos últimos filmes de ação. 0 efeito do capuz é uma total amnésia sobre quem eles são fora da sala. Eles têm a capacidade de julgar - talvez por imagens e combinações de imagens, por cheiros e ruídos, não necessariamente por palavras -, mas não sabem se lá fora são índios Kaxinawá ou aborígenes australianos; se são migrantes ilegais bolivianos trabalhando em suadouros têxteis de São Paulo ou se são os donos das etiquetas que se utilizam do trabalho terceirizado desses imigrantes; não sabem se são pobres ou ricos, músicos ou operários, mulheres ou bears, gays ou lésbicas, negras ou brancos, galinhas ou gatos, onças ou baleias. Pensem no que quiserem: árvores, pedras. 0 que precisam fazer é chegar a um consenso sobre princípios de justiça que no mínimo protejam seus direitos à diversidade e à vida digna conforme seus modos de vida. Essas cidadãs e cidadãos, diz Rawls, podem pensar assim: "- Tenho que proteger-me com direitos no melhor dos casos - caso eu seja lá fora branco, rico, homem, nova-iorquino". Por outro lado, eles podem raciocinar também assim: "É, mas preciso de proteção caso lá fora eu seja mulher negra, pobre e mãe-solteira; o pior é se eu voltar à existência como lagosta ou um rato de laboratório". Seguindo essa linha de pensamento, Rawls chega à ideia de um piso mínimo de direitos humanos ao mesmo tempo gerais e diferenciados, que são essencialmente direitos aos meios para desenvolver as faculdades humanas e não-humanas: o que significa adquirir disposições do corpo e da mente, e significa a capacidade de desenvolver modos diferentes de existir. Há outras maneiras de chegar a alianças interessantes entre humanos e animais, que em lugar de partir da suposição de uma racionalidade coletiva que se forma em experimentos de pensamento como o de Rawls, ou no debate público como requer Habermas, apoiam-se em relações de empatia na dor e pela alegria. 0 que importa aqui é o uso da imaginação para ir além da constatação do estado de coisas.

\section{PALAVRas Finais}

"Sonhamos com uma outra via" - porque a Antropologia não é a ciência do pessimismo. Essa outra via é o uso prolongado da diferença tendo como seu fim 0 usufruto da vida (BARBOSA DE ALMEIDA, 2008). Ela está desenhada nos exemplos de modos alternativos de vida social oferecidos pela diversidade de povos 
indígenas, de povos afrodescendentes, de povos mestiços-camponeses, que ocupam - ou transitam por - diferentes sistemas humano-naturais na América. Os exemplos atravessam o continente, indo dos povos nômades guarani e dos tradicionais caiçaras do litoral atlântico aos "isolados" do Javari e do Juruá no sopé dos Andes orientais, subindo a cordilheira e descendo até o Pacífico. Esses exemplos constituem um reservatório de paisagens, de entes vivos, de corpos naturais, de artefatos, musicalidades, cozinhas, regimes de uso e de circulação de bens, nominações e parentescos, festas e ontologias - cuja perda destrutiva será lamentada pelas civilizações do futuro.

As disputas por territorialidades físicas se combinam agora com a resistência de metafísicas territorializadas - outro nome para cosmologias e mitologias ameríndias e afrodescendentes, par a par com nossas cosmologias e mitologias mais conhecidas como ontologias e filosofias. Trata-se também de disputas pelo direito ao reconhecimento da existência da pluralidade de ciências indígenas e camponesas - sementes virtuais, que já começam a proliferar em rede, de universidades do futuro que escaparão, com apoio nas mais recentes técnicas, do modelo ainda medieval do saber enclausurado nas academias. Em suma, as questões de territorialidade se imbricam em questões de metafísica - a metafísica indígena que vê nas pedras seus antepassados, que vê no chão a presença dos antigos, que vê nos astros atores de dramas terrestres. Por isso, não há conflito digno de nota entre a Antropologia das territorialidades e a Antropologia das ontologias e socialidades porque, longe de se excluírem, é evidente que é preciso olhar para o invisível - seja ele chamado ambiciosamente de comunismo, ou de uma vida bastantemente boa - para que haja ânimo de lutar pelo visível, que é o chão onde a vida real é vivida (BARBOSA DE ALMEIDA, 2008).

\section{REFERÊNCIAS}

ADORNO, Theodor W. Gesellschaftstheorie und Kulturkritik. Frankfurt am Main: Suhrkamp, 1975.

AFFONSO DA COSTA, Newton C. O Conhecimento Científico. São Paulo: Discurso Editorial, 1997.

AFFONSO DA COSTA, Newton C.; FRENCH, Steven. Science and Partial Truth: A Unitary Approach to Models and Scientific Reasoning. Oxford: Oxford University Press, 2003. 
BARBOSA DE ALMEIDA, Mauro W. A Enciclopédia da Floresta e a Florestania. Página 20, 3 de janeiro de 2008.

BARRINGTON MOORE JR. Social Origins of Dictatorship and Democracy. Lord and Peasant in the Making of the Modern World. Boston: Beacon Press, 1966.

BENKLER, Yochai. The Wealth of Networks: How Social Production Transforms markets and Freedom. New Haven: Yale University Press, 2006.

CHOMSKY, Noam. Necessary Illusions: Thought Control in Democratic Societies. London: Pluto Press, 1989.

CHOMSKY, Noam. Powers and prospects: reflections on human nature and the social order. London: Pluto Press, 1996.

COFFACI DE LIMA, Edilene; BARBOSA DE ALMEIDA, Mauro W.; IGLESIAS, Marcelo P. Petróleo, gás, estradas e populações tradicionais no Alto Juruá. Página 20, 29 e 30 de abril de 2007.

DANOWSKI, Déborah; VIVEIROS DE CASTRO, Eduardo B. Há Mundo por Vir? Ensaio sobre os Medos e os Fins. Desterro: Cultura e Barbárie/Instituto Socioambiental, 2014.

DARWIN, Charles. On the Origin of Species. A Facsimile of the First Editon with na Introduction by Enst Mayr. Cambridge: Harvard University Press, 1964.

DELEUZE, Gilles; GUATTARI, Félix. Capitalisme et Schizophrénie 2. Mille Plateaux. Paris: Éditions Minuit, 1980.

ELSTER, Jon. Local Justice: How Institutions Allocate Scarce Goods. New York: Russel Sage Foundation, 1992.

FARAGE, Nádia. No Collar, No Master: Workers and Animals in the Modernization of Rio de Janeiro 1903-1904. Open Anthropology Cooperative, Working Paper Series n. 18, 2013. Disponível em:

< http://openanthcoop.net/press/2013/11/11/no-collar-no-master/> . Acessado em 19 de junho de 2015.

FERGUSON, Charles E. Microeconomia. Rio de Janeiro: Forense-Universitária, 1985.

FERREIRA, Pedro P. 2015. Skatografias: o caso do "pico". In: KOFES, Suely; MANICA, Daniela (Orgs.). Vida \& Grafias: narrativas antropológicas, entre biografia e etnografia. Rio de Janeiro: Lamparina, 2015, p. 9-15. 
FEYNMAN, Richard P. The Feyman Lectures on Physics: Mainly Mechanics, Radiation and Heat. Reading: Addison-Wesley, 1963.

FLORIDI, Luciano. Skepticism and animal rationality: the fortune of Chrysippus`s $\mathrm{dog}$ in the history of Western thought. Archiv für Geschichte der Philosophie, $\mathrm{n}^{0}$ 79, 1997, p. 27-57.

FOUCAULT, Michel. Dits et Écrits. I. 1954-1988. II. 1970-1975. Paris: Gallimard, 1985.

GEORGESCU-ROEGEN, Nicholas. The Entropy Law and the Economic Process in Retrospect. Eastern Economic Journal, vol. 12, n 1, 1986, p. 3-18.

GRAMSCI, Antonio. Quaderni del Carcere. 4 vols. Turim: Giulio Einaudi, 1875. GREGORY, Chris. Gifts and Commodities. Londres: Academic Press, 1982.

HABERMAS, Jürgen. Der philosophische Diskurs der Moderne. Frankfurt no Meno: Surkhamp, 1988.

HACKING, Ian. Historical Ontology. Massachusetts: Harvard University Press, 2004.

HILDENBRAND, Werner; KIRMAN, Alan P. Introduction to Equilibrium Analysis: Variations on Themes by Edgewort and Walras. Amsterdam: North-Holland, 1976.

HORKHEIMER, Max; ADORNO, Theodor. Dialectic of Enlightenment. New York: The Seabury Press, 1972.

IBAMA-ICMBio. Parecer Técnico N. 03/2013. Brasília: Grupo de Trabalho Interinstitucional de Atividades de Exploração de Produção de Óleo e Gás, 2013.

KANT, Immanuel. Kritik der reinen Vernunft. Stuttgart: Philipp Reclam, 1966.

KÜMMEL, Reiner. The Second Law of Economics: Energy, Entropy, and the Origins of Wealth. New York: Springer, 2011.

LUXEMBURG, Rosa. A Acumulação do Capital: Estudo sobre a Interpretação Econômica do Imperialismo. Rio de Janeiro: Zahar, 1970.

MARCUSE, Herbert. A Ideologia da Sociedade Industrial. Rio de Janeiro: Zahar, 1967.

MARCUSE, Herbert. Razão e Revolução: Hegel e o advento da Teoria Social. Rio de Janeiro: Paz e Terra, 1978.

MAURY, Jean-Pierre. Carnot et la Machine a Vapeur. Paris: Presses Universitaires de France, 1986. 
MESQUITA, Erika. Ver de perto pra contar de certo. As mudanças climáticas sob os olhares dos moradores da floresta do Alto Juruá. Tese de Doutorado, Ciências Sociais, Universidade Estadual de Campinas, Campinas, 2012.

OPIAC (Organização dos Professores Indígenas do Acre); ASSOCIAÇÃO APIWTXA DO RIO AMÔNEA; APIH (Associação do Povo Arara do Igarape Humaitá); AIN (Associação do Povo Indígena Nukini da República). Carta Declaratória sobre a Prospecção e Exploração de Petróleo e Gás no Juruá, 2012. Disponível em: $<$ http://www.gta.org.br/newspost/carta-declaratoria-sobre-a-prospeccao-eexploracao-de-petroleo-e-gas-no-jurua/ > . Acesso em 19 de junho de 2015.

PARETO, Vilfredo. Mathematical Economics. International Economic Papers, vol. 5, 1955, p. 58-103.

PLATÃO. A República. São Paulo: Difel, 1973.

RAWLS, John. A Theory of Justice. Harvard: Harvard University Press, 1971.

SAMUELSON, Paul. Economics. 10ª . Edição. New York: McGraw-Hill, 1976.

SCHOPENHAUER, Arthur. Die Welt als Wille und Vorstellung (Vol. 1). Zürich: Haffmans Verlag, 1998.

SCOTT, James. The Moral Economy of the Peasant. Rebellion and Subsistence in Southeast Asia. Princeton: Princeton University Press, 1976.

SEN, Amartya. On Ethics and Economics. Oxford: Basil Blackwell, 1987.

SEVÁ, Oswaldo. 0 Petróleo e o Gás (I e II). Página Vinte, Rio Branco (AC), 25 de março e 1 de abril de 2007.

SEVÁ, Oswaldo. Ofensiva do capital contra os povos indígenas e camponeses é global. Desinformémonos. Disponível em:

$<$ http://desinformemonos.org.mx/2011/02/ofensiva-do-capital-contra-os-povosindigenas-e-camponeses-e-global/> . Acesso em 19 de junho de 2015.

SEVÁ, Oswaldo; PIEDRAFITA, Marcelo. 0 Petróleo e o Gás (III). Página Vinte, Rio Branco (AC), 15 de abril de 2007.

SÜSSEKIND, Felipe. No Rastro da Onça Pantaneira: Cartografia de uma presença indicial. Tese de Doutorado, Antropologia, Museu Nacional/Universidade Federal do Rio de Janeiro, 2010.

THOMPSON, Edward P. Customs in Common: Studies in Traditional Popular Culture. Londres: Merlin Press, 1991. 
TOMÁS DE AQUINO, São. Suma Teológica III. Seção I, Parte II. São Paulo: Loyola, 2005.

WALLACE, Alfred R. On the Tendency of Varieties to depart indefinitely from the Original Type. 1858. Disponivel em:

< http://people.wku.edu/charles.smith/wallace/S043.htm>. Acessado em 19 de junho de 2015. 